which occupies the greater part of the book, is that in attempting to be comprehensive it fails to evaluate sufficiently-the highly significant work of the League in the field of nutrition, for example, receives the barest mention. The work of the Permanent Court of International Justice and of the International Labour Organisation are dealt with in the third part ; the final section of the book containing the text of the Covenant and extracts from the Statute of the Permanent Court and from the Constitution of the International Labour Organisation.

\section{Hospitals in War Time}

The Minister of Health has issued to all hospital authorities and voluntary hospitals a memorandum explaining the main lines on which a scheme for a war-time hospital organization is being worked out for England and Wales (Emergency Medical Services Memorandum 2. H.M. Stationery Office. 6d. net). The basis of the emergency scheme is the division of hospitals into different classes according to the use which it is intended that they should serve, and almost all hospitals are included in some way. Room is to be made for the reception of casualties in one wing or block of most of the mental hospitals in the country, and a few mental hospitals are to be cleared of their ordinary patients. It is proposed to link up casualty hospitals to each other in the more vulnerable areas and to selected hospitals farther away. In order to increase the hospital accommodation, all hospitals would be asked to discharge all patients for whom institutional treatment is not essential, which it is estimated would probably free from 30 to 50 per cent of the existing hospital beds, and additional beds would be introduced into selected hospitals and institutions. Proposals for the organization of the medical and nursing staffs are also outlined.

\section{Physical and Mental Welfare}

The Physical and Mental Welfare Society of New Zealand, Onehunga, N.Z., suggests that the centenary of New Zealand, might be celebrated by the foundation of a memorial, and that this might take the form of an endowed scheme whereby the 'masses' might be kept in touch with scientific truths and views bearing upon the physical and mental welfare of the race. New Zealand was recognized as an independent Colony in 1841. Bearing on this subject, the Health Organisation of the League of Nations has issued reports on physical education and on nutrition (Bull. Health Organisation, 7, No. 4, 1938. Allen and Unwin, Museum Street, W.C.1. 2s. 6d.). The first report suggests a programme of laboratory research upon the effects of physical exercise, and on the relation between intellectual and physical development. The other report deals with principles to be observed in the study of diets and of the nutrition of a population, particularly as regards nutrition in the tropics.

\section{Disposal of Offal}

IN the Benjamin Ward Richardson Lecture recently delivered at the Royal Sanitary Institute, Mr. John Austin dealt with the hygienic treatment and disposal of offal and by-products in abattoirs. $\mathrm{He}$ said that two most important considerations govern the treatment of animal offal, namely, (1) the hygienic disposal of animal waste matter, and (2) its economic utilization. Suitable premises are needed to which all raw material can be brought from the slaughter-hall with the minimum amount of handling ; they should be well lighted and ventilated and provided with an abundant supply of steam and hot and cold water. Mr. Austin then considered by-product work under the headings of blood, hides and skins, tripe, casings, edible fat and inedible offal, all of which require immediate treatment owing to the rapidity of decomposition after slaughter.

\section{British Chemical Industry}

A survey of the achievements of British chemical industry in the last twenty-five years was given by Sir Gilbert T. Morgan in three Cantor Lectures to the Royal Society of Arts which have just been published. The field covered included inorganic chemicals, gases, nitrogen products, pigments, electrochemistry, metals, the utilization of coal, explosives, dyes, fermentation, plastics and drugs, and the lectures give a valuable survey of modern processes and the progress made in the period considered.

\section{Centro Volpi Di Elettrologia}

The second number of this journal (English edition) mentions that amongst the first of its activities will be a convention for the development of 'experimentations' in view of industrial autarchy. In order to develop research work, which is the basis of industrial emancipation, Italian industrialists and the most competent scientific workers and technicians of the country will meet in Venice during October 26-28. They will examine the many sides of the problem of the improvement of existing laboratories, the creation of new ones and the co-operative work between them. The centre extends its welcome to all those who wish to attend the conventions. In the field of international relations the Centre is endeavouring to establish collaboration.

\section{Safeguarding of Unpublished Research}

Such attemp's as were made by individuals or institutions to remove important papors to places of greater safety during the September crisis merely served to emphasize the impossibility of handling at short notice the quantity of material involved. The Research Co-ordination Committee accordingly decided to continue its investigation of the possibilities of micro-film technique. In view of recent international developments, the steps taken by the Research Co-ordination Committee to facilitate the reproduction and storage of documents are particularly timely. The process was described in NATURE of March 11, p. 393. Briefly, it consists in photographing documents of any kind, such as charts, pages of books, loose sheets, maps, etc., on to standard $35 \mathrm{~mm}$. cine-film. Documents up to $17 \mathrm{in.} \times$ 24 in. can be dealt with (or larger ones in two or 
more sections). The photographs are preserved in negative form on acetate safety film, which when tightly rolled is far more resistant to fire than any paper record. Working with quarto papers (10 in. $\times$ 8 in.), 1600 facsimiles can be obtained on $100 \mathrm{ft}$. of film. This micro-record occupies only one twentieth of the volume of the original. Full-size prints can be made from it at any time, or it can be read in a special projector, or thrown on a wall-screen for lectures. Preliminary arrangements are in hand for making micro-film records at the cost of one halfpenny per quarto document, possibly less if a sufficient volume of material is handled. Further information may be obtained from the Hon. Secretary, Research Co-ordination Committee, 35 Gordon Square, London, W.C.2.

\section{Old Science and Medicine}

E. P. Goldschmint AND Co., Ltd., of 45 Old Bond Street, have recently issued three catalogues entitled respectively "Science and Medicine", "English Science and Medicine" and "Old Medical Books". The first catalogue contains entries of a complete set in thirteen volumes of Johann Peter Frank's "Complete System of Medical Polity", the first edition of De Kempelen's works on the talking machine, the first German edition of Kepler's "Steriometria" and numerous original papers by Pasteur, Scheel and others. In the catalogue on "English Science and Medicine" we note the rare third edition of Harvey's "De Motu Cordis", Gilbert's "De Magnete", several works by Robert Boyle, including that on "The Mechanical Origine of Production of divers particular Qualities . . . of Magnetical Qualities", the first work on electricity in English, the first edition of Sir Robert Dudley's "Arcano del Mare", one of the foremost English works on navigation and several modern works by Huxley, Galton, Rutherford, Banting and Best, among others. Among the most notable works in the catalogue of "Old Medical Books" are the first edition of John Vigo's treatise on surgery in black letter (1543), the first illustrated edition of Dioscorides (1543), Sir Theodore Turquet de Mayerne's work on arthritis (1676), and the first editions of Laennec's book on auscultation (1819) and Semmelweis's on puerperal fever (1861).

\section{Eclipse of the Sun on April I9}

AN annular eclipse of the sun, partly visible as a partial eclipse from the British Isles, occurs on April 19 next. The annular phase is visible in Alaska and the Arctic Ocean. At Greenwich, the eclipse begins at $17^{\mathrm{h}} 29^{\mathrm{m}}$, the greatest phase $(0 \cdot 36)$ being reached at $18^{\mathrm{h}} 18^{\mathrm{m}}$; sunset is at $19^{\mathrm{h}} 2^{\mathrm{m}}$, just before the eclipse ends. The position angle of first contact is $298^{\circ}$ from the north point of the sun's image or $258^{\circ}$ from the vertex. At Edinburgh the corresponding times are : beginning $17^{\mathrm{h}} 17^{\mathrm{m}}$; greatest phase $(0 \cdot 44)$ at $18^{\mathrm{h}} 12^{\mathrm{m}}$; ending at $19^{\mathrm{h}} 3^{\mathrm{m}}$. The above times are in Universal Time; add $1 \mathrm{~h}$. to convert to Summer Time.

\section{The Night Sky in April}

THE moon is full on April 4 at $4 \cdot 3^{\mathrm{h}}$ and new on April 19 at $16 \cdot 6^{\mathrm{h}}$. The altitude of the full moon at transit at Greenwich on April $5^{\mathrm{d}} 0^{\mathrm{h}} 43^{\mathrm{m}}$ is $27 \frac{1}{2}^{\circ}$. Lunar conjunctions with the planets occur as follows : on April 10 with Mars; on April 16 with Venus; on April 17 with Jupiter; and on April 18 with Mercury. On April 22, Venus is in conjunction with Jupiter, the geocentric separation of the planets being only $0 \cdot 4^{\circ}$. The two planets rise, however, less than one hour before the sun. Mercury is at inferior conjunction with the sun on April 3 and is therefore not visible. Saturn is in conjunction on April 11 and likewise rises and sets with the sun. Mars still remains a morning star, rising about $1 \frac{1}{2}$ h in midApril. The only bright stars occulted during the month are $\psi$ Ophiuchi (mag. 4.6) on April 8 at $2^{\text {h }} 2 \cdot 9^{\mathrm{m}}$ (reappearance) as seen from Greenwich, and 26 Geminorum (mag. $5 \cdot 1$ ) on April 24 at $22^{\mathrm{h}} 12 \cdot 1^{\mathrm{m}}$ (disappearance). The Lyrid meteors, the radiant of which is near 104 Herculis, are due at their maximum between April 19 and 22, but in some years they are nearly absent. All the above times are given in universal time (U.T.). Summer Time begins on April 16.

\section{Announcements}

Mr. J. E. Montgomrey has been appointed secretary of the Institution of Mechanical Engineers in succession to Brigadier-General Magnus Mowat, who has retired on account of ill-health. Mr. Montgomrey has been assistant secretary of the Institution since 1920 .

THE Rockefeller Foundation has announced that during the next seven years it will grant a sum not exceeding $£ 12,000$ to the Imperial College of Science and Technology, South Kensington, for research on vitamins, sterols and related compounds under the direction of Prof. I. M. Heilbron.

AN Institute for Research in Aeronautical Medicine has recently been founded at Mount Fuji, Japan.

IN 1938 the number of deaths in France was 40,000 higher than the number of births, while in Italy the births exceeded the deaths by 424,000 and in Germany by 500,000 .

THE University of Peiping, which was closed at an earlier stage of the Sino-Japanese War, has recently been reopened under the direction of Prof. Hisomu Nagat, formerly of the University of Formosa.

We have received a part of the Collection Scientifique issued by the Institut Internationale de Coopération Intellectuelle (1938), entitled "Les déterminations physico-chimiques des poids moléculaires et atomiques des gaz", price 45 francs. The volume contains papers by Moles, Whytlaw-Gray, Cawood, Keesom and others, a long discussion and addenda. 